\title{
Introduction
}

\section{'Whose Anthropology Is It, Anyway?'}

\section{Benjamin O. L. Bowles and Federica Guglielmo}

Only connect!

(Forster 2013: Ch. 22)

This special issue of Anthropology in Action collects essays arising from the 4th Post-graduate Conference of the Royal Anthropological Institute, held at Brunel University (London) on 3-4 September 2014. The event aimed to explore a variety of perspectives concerning the production and the ownership of anthropological knowledge, including issues of authority and ethical responsibility. We also welcomed reflections on the opening of new interstitial fieldsites in between the structured components of anthropological research. Our interest focused on the dilemmas arising from the definition of the field itself, in the guise of the epistemological delimitation of its boundaries and how these affect the relational world within it. We focused on the co-dependence between these factors and on the influence of increasing interconnectedness through advanced and progressively widespread communication technologies (cf. Kelty 2009).

The scholarship on fieldwork that could inspire our work is vast. In drafting our call for paper, however, we were influenced by Edmund Leach's Reith Lectures, A Runaway World (1967), through which he argued the importance of a scientific awareness of 'the evolving system as a whole' against epistemological reductionism (Leach 1967; cf. also Tambiah 2002). As Grimshaw observed, the title carried within itself a 'mixture of optimism and fear', highlighting how Leach's 'interest was in movement, not stasis; [...] he articulated the problem as one of disjunction, of reconciling the reality of change with conventional notions and cultural categories which guaranteed order' (1990: 77). Leach 'warned against withdrawal [...] masqueraded as scientific objectivity', which translated in a sense of estrangement of the man from the 'world out there' (ibid.: 77-8). Significantly, his last lecture was titled after Forster's poem ‘Only Connect
...' (1999), giving Leach the frame to his conclusive invitation to 'live in fragments no longer'.

Leach was concerned with the expansion and progressive discontinuity in the experience and production of knowledge, its compartmentalisation and, thus, about the inclination of the discipline towards it. The concern over the dialectics between the general and the particular in the discipline had surfaced in a time of crisis and redefinition of anthropology, and has done so recursively since this time of introspection and reassessment (cf. Appadurai 1988; Clifford and Marcus 1986; GDAT in Rapport 2009; Wolf 1980).

As graduate students recently back from quite diverse fieldwork settings, we felt that the production of anthropological knowledge as a result of inter-action - as something else altogether compared to its single components - had often been glossed over in its most recent developments. We noted the tendency for ethnography to privilege the 'heroic' anthropologists and their quest for understanding, often framing research through its successes and minimising its failures, and thus making fieldwork appear as a journey from personal ignorance to personal enlightenment and revelation. Quite apart from their fetishisation of 'success' within the fieldwork process, such accounts are inclined to minimise the role of those other than the anthropologist, their understandings and their knowledge production. Interconnectedness, we had begun to realise, had had a considerable impact on how we conducted research and surfaced as an additional dimension of the research process.

Our different experiences had led us to rethink several classificatory terms and concepts that were meant to define (in its etymological meaning of reaching completion through the establishment of finis, of boundaries) our experiences: from the mere location of the field, whether 'at home' or far away, to the idea of 'far away' itself - how 'far' is 'away'? In a moment of technological (r)evolution, of migration beyond 
merely geographical boundaries, of increased selfawareness of identities as global, does fieldwork - as experience defined, again, in time and space - ever end? For many of us, 'dislocating perspective' on the construction of the field as 'autonomous units of practice and analysis' (Collins and Coleman 2006: 2) is no longer a viable option, and the ethnographic artifice (cf. Darnell 2001) requires in this instance an intellectual effort that should probably not be encouraged. In this regard, Candea (2007) makes a compelling critique of Marcus (1995) in defence of bounded fieldsites. He upholds work which is conducted within 'arbitrary locations', spaces delineated by the researcher for heuristic purposes, that the bounded fieldsite is always a fictional construct, often useful to think with, but dangerous if reified.

In itself, this concept - rather, this epistemological necessity - is not new. Challenges to the role of the anthropologist 'as producer of text, and to [the] place as container of culture' (Collins and Coleman 2006: 2) have been central to the discipline since the 1970s (cf. also Marcus and Fischer 1986). What is new, however, is the context in which it applies.

The realities of ethnographic research in the modern world are differently and more complexly connected than the world Leach was describing, and the concept of interconnectedness has taken up new meanings. The experience of globalisation helps the discipline get rid of the ideological conceptions concerning 'traditional societies' (cf. Rapport 2009: 110) reframing relationships along different lines of proximity. These sociopolitical changes, moving contemporarily as centrifugal and centripetal forces, are among the factors which make the traditional model of the anthropologist as a powerful outsider appear increasingly anachronistic. Now that our participants can follow us and even research us through social networks, through those same technologies that make up a growing component of our processes of gathering data, and now that staying in close contact with our participants is a normal part of the after-fieldwork process, where is the field situated and what is our role in it? Can we 'leave the field' in a straightforward manner even after we physically leave our locality of study? How is the interconnectedness between persons and locations affecting how anthropologists can become ethically engaged actors in the field? How does the mutual training of our collaborators as collaborators, and of us as researchers, affect the production and the ownership of anthropological knowledge - and how do so the institutions to which we are bound, ethically and financially?

In order to foster a shared reflection on new ways of understanding the field and its agents, we invited
PhD students and early-career researchers to foster an environment conducive to new methodological and theoretical insights across diverse fields. The set of questions we posed was intentionally broad, as we aimed to encourage a spirit of collaboration in this new generation of scholars regardless of the normal barriers of research interest or country of study, in the hope of raising certain germane questions concerning the reality of fieldwork in regard to authorship and the selectiveness of data. These questions led us to reflect on new and more engaged methods of fieldwork within anthropology; methods grounded on a deeper collaboration between the ethnographer and the field, with greater input from informants through the means of reflexive narratives such as photography, social media accounts, or online blogs, and the consequent awareness of our 'subjects of study'. Indeed, in an increasingly interconnected world, we wondered if it is not pertinent to ask whose anthropology is this, and in doing so coined the phrase which would become first the title and theme of our conference, and now of this publication.

The conference was an opportunity to bring together those researchers with the most telling insights into the modern fieldwork condition; those who had only recently returned from putting the methodological textbooks to the test, and thereby finding their limitations, in fieldsites around the world. Our core ideas - initially focused on the transformative power of new technologies when applied to the fieldwork dynamics, and on the possibility of a more deeply collaborative anthropology - were engaged with enthusiastically by the delegates. These ideas were expanded on and taken in new directions in ways which we could not have predicted, a fact reflected in the range of scholarship presented in this volume. Particularly noticeable was the range of fresh and innovative methodological approaches taken by our presenters in their fields. We had asked for approaches that looked at the taken-for-granted boundaries of the field, but we did not expect the degree to which authors would challenge longstanding anthropological certainties and propose radical solutions to problems. The essays selected for this issue, we feel, have shown significantly broad insights in understanding and using methodology towards a new awareness of the field. The task of writing an introduction to what appear to be such diverse contributions is, thus, a difficult one.

The articles presented below are to be read individually as important new additions to particular fields and topics, but can also be taken together as a snapshot of the work which is being done by a new 
cohort of fieldworkers. Both perspectives will highlight the will to integrate methods other than the usual fieldnote diaries and interview transcripts into their work and sensitive to the peculiar fieldwork demands of the contemporary interconnected world. All have been selected for their ability to combine methodological novelty with classic anthropological methods, themes and analysis.

When reviewing our choices for inclusion, we realised that there were certain similarities between these apparently disparate articles, and we shall introduce what we feel to be the most important continuities included therein; the articles have been formally grouped around the main themes that we see emerging - the ownership and production of anthropological knowledge; the tension of fieldwork intersubjectivities; the entanglement between institutionalised moralities and the ambiguity of the anthropologist's position. In that, we realise that further intersections among these themes are more than evident, and that the order of presentation could be subverted in several ways. We introduce one possible line of interpretation as a limited overview of the major themes of this edition, urging the readers to let the ethnographies speak for themselves.

\section{Ownership}

As described above, our conference raised questions regarding the entanglement between the definition of fieldwork, the actors that participate in it, and the production and ownership of knowledge. The contributors to this issue provide different answers to our questions. Despite these differences, the willingness and ability to recognise and elicit unclichéd tropes into their fieldwork processes has become a major theme of the conversation.

A first instance of this particular approach is represented by Ben Belek, 'Managing an Autistic Heart', which revolves on a central case study of a young woman named Victoria. The author makes principle use of Victoria's online blog posts, which he supplements with insights garnered from twelve months of more traditional ethnographic data collection and other online interactions via social networks. Belek draws on Victoria's intensely personal narrative in terms of meta-data, foregrounding her voice so as to allow Victoria to speak for herself, thus realising a thick description of the subjective experience of managing emotions as a person with autism, while overcoming the shortcomings of artificial interviewing and fostering proximity. Belek demonstrates that the dis- tancing effect of the Internet, including the time which can be taken to gather thoughts and self-edit, can make blog posts a great source of data when dealing with such deeply personal topics rooted in personal emotional experience. He uses this strong methodology to make a theoretical point, namely that evidence from autistic adults - or, more broadly, the particular neurological condition of our participants - should be considered as part of the network which makes up an individual's social experience.

Where Belek uses blog posts to great effect, Oliver Pattenden, in his 'Relations of Trust, Questions about Expectations', attends to his participants' voices through their own words and their own self-curated work. The author describes how he initiated a project called My Future, whereby the schoolchildren with whom he was working were encouraged to draw diagrams and use disposable cameras to represent their moral judgements. Such a collaborative project between anthropologist and participants takes the selective authority of the former's gaze to enable the latter's, eliciting the central role of photography as tool of the participants. While this method is used elsewhere, particularly in visual anthropology (cf. Harper 2002), Pattenden's contribution relies on bridging the boundaries between data and metadata.

\section{Bridging Boundaries}

Through rather different means, the elicitation of narratives is also the theme of Karen Lane's 'Canine Connections', where she interrogates the ethnographer's positioning in the field through an innovative representation of research collaboration. In her research into muted narratives in the divided Northern Irish city of Belfast, Lane was accompanied throughout by her pet dog, Torridon. According to Lane, Torridon's canine identity was crucial in constructing her as a particular kind of gatekeeper. Lane provides a detailed description of how Torridon affected her interactions in the field, making certain connections, potentially limiting others, and ultimately collecting particular sorts of data in a fashion which made Torridon a generator of information, or at least an important component in the network of relationships in which the field data were gathered. Lane's work can be viewed both as part of an ongoing project to appreciate properly the role of non-human animals in social worlds (Haraway 2008; Knight 2005), but also as a call for anthropologists to consider how they appear in the field, and with whom. Lane concludes that Torridon enabled the dynamic interconnectedness that 
Leach urges in the discipline and, in the spirit of this conclusion, it is necessary to reflect on the establishment of our own connections in the field. Seeing nonhuman animals not instrumentally, as tools, but as collaborators and assistants to our data collection, is novel and presents many possibilities for ethnographers wishing to follow Lane's lead and to expand the circle of what we recognise as the co-producers of fieldwork realities.

Such co-production takes place in the understanding of the researcher herself as an agent who, perhaps more than others, refracts identities. This is the theme analysed by Sangmi Lee, who moves beyond the identity of the ethnographer as itself the subject of investigation of behalf of the research participants; instead, Lee's fieldwork, as presented in 'Questions from the Field', entails the exploration and analysis of the very questions she had herself been posed over the course of her time in the field. It is not uncommon for anthropologists to see their identity translated - at times, to an unfruitful extent (cf. Owen 2003) - in the field according to emic categories. Lee's article aims at employing such categories as an analytical paradigm towards the production of ethnography. By questioning the 'means and motives' of anthropological research, Lee engages with a twofold mediation of representation: she reflects on the relationship of mutual identification between herself and her collaborators; through the same epistemological approach, she considers the issues of representations of selves - hers and her informants' - throughout the writing-up process. Lee gives new meaning to the 'heroism' of the anthropologist by showing how hindrances in the field can be an essential contribution to the production of knowledge.

\section{Para-sites}

While the previous articles have discussed the ownership of knowledge and its co-production, Sitara Thobani's exploration of postcolonial representation considers the corporeality of historical discourses on Indian traditional dances. In 'Living History, Performing Coloniality', contemporary South Asian dance performances in Britain are analysed for what they can reveal about colonial history, processes of orientalism and discourses of sexuality; as the author argues, the performative narrativisation of history and of idealised femininity through the dance prove valuable in exploring the capacity of coloniality to endure as well we transform in its enunciations. Thobani addresses dance performances as 'paradigmatic scenes', richly textured and layered occurrences which can be analytically unpacked in order to show their symbolic and material significance. Dance performance is here vessel for exploring varied themes and historical trends, but the essay also deals diachronically with dance forms and trends going far back into South Asian history. This article bridges between the study of contemporary dance performance and archival analysis, producing a rich diachronic account of bodily practises in relation to colonial and orientalist processes.

Thobani's shift of attention can be further appreciated in Paul Gilbert's analysis of research with elite groups. In 'Trouble in Para-sites', Gilbert employs and then critically examines Marcus' (1995) proposed method when working across multiple sites with local elites of creating 'para-sites' of collaboration which integrate with, and when necessary defer to, those with expert local knowledge. Gilbert describes his own attempt to create a 'para-site' with members of London's mining industry elites. He interrogates how such a collaborative enterprise works practically and ethically when in relation to powerful epistemic elites who are usually scorned, avoided or distrusted in what he calls anthropology's 'ritualised declarations of disloyalty' to the rich and powerful. In doing so, Marcus' theory is put to a rigorous test with one of the most powerful epistemic elites in contemporary capitalism. Gilbert evaluates merits of collaborative work and aspects of avoidance and resistance, finding power in ambiguity. For Gilbert, the ethnographer represents the trickster, between the powerful and the powerless, dwelling outside of the restrictions of moral and epistemic certainties.

\section{Conclusions}

The aforementioned ethnographies have direct relevance in describing how the position of the anthropologist is refracted in the production of knowledge. Transversally, this theme entangles with definitions of the field (Belek, Thobani, Gilbert), its actors (Pattenden, Lane), the definition itself of anthropologist (Lee, Gilbert) and of data (Lane, Thobani, Gilbert). The articles all raise interesting arguments concerning how one's position in the field can affect the quality of data, particularly in relation to the informants' moral frameworks. More importantly, they develop this reflection through the methodologies and ways of being in the field, which must not be written out of ethnographic texts. The other major trend linking these apparently disparate ethnographies is that many of them 
raise important questions, and offer certain answers, on the subject of how the ethnographer is currently, and should be, (re)positioned and perceived in the field, showing incisive self awareness of the researcher as a situated participant to social lives.

These novel methodological solutions, theoretical advances and ways of viewing the anthropologist positioned within their complex and interconnected fields are but a few of the central concerns of the rich ethnographic volume. We aim for these pieces to provoke comment, discussion and argument. 'Whose Anthropology is it, anyway?' remains a pressing question for us and, we believe, for many fieldworkers to answer. We hope that this question and our proposed answers become part of an ongoing discussion within anthropology on how to be an engaged and ethical fieldworker in an increasingly interconnected world.

\section{Acknowledgements}

We wish to thank the Royal Anthropological Institute, Brunel University and its Department of Anthropology, with special regard to our colleagues on the organising committee, for making the conference which inspired this issue come to fruition. Our gratitude is also due to each and every attendee and presenter at that conference for contributing to the thought-provoking milieu in which these essays came to light. Finally, we would like to thank the reviewers and the editorial team at Anthropology in Action for their comments and guidance.

Benjamin O. L. Bowles is a recent $\mathrm{PhD}$ graduate from Brunel University (London). He is also a visiting lecturer at the University of Roehampton. His research is with itinerant boat-dwellers on the waterways of London and South East England and focuses on the relationship between travelling peoples and nationstates. E-mail: benjaminolbowles@gmail.com

Federica Guglielmo is PhD candidate in Medical Anthropology at Brunel University (London). Her doctoral research focuses on the moral construction of social identities in the aftermath of the Rwandan genocide. E-mail: federica.guglielmo@gmail.com

\section{Notes}

1. The call for paper was drafted in concert with other members of the organising committee - Adam Con- nelly, Nicole I. J. Hoellerer and Eva Luksaite - to whom we are extremely grateful.

2. As the Reith Lectures address a public of non-specialists, Leach's argument acquired the traits of a moral call in the aftermath of the Second World War.

3. Whose Anthropology is it, anyway? was inspired by the famous comedy show Whose line is it, anyway? (1998-2006).

\section{References}

Appadurai, A. (1988), 'Introduction: Place and Voice in Anthropological Theory', Cultural Anthropology no. 3: 16-20. doi: 10.1525/can.1988.3.1.02a00020

Candea, M. (2007), 'Arbitrary Locations: In Defense of the Bounded Field-site', Journal of the Royal Anthropological Institute 13, no. 1: 167-84.

Clifford, J. and G. Marcus (eds.) (1986), Writing Culture: The Poetics and Politics of Ethnography (Berkley: University of California Press).

Collins, P. and S. Coleman (eds.) (2006), Locating the Field: Space, Place and Context in Anthropology (Oxford: Berg).

Darnell, R. (2001), Invisible Genealogies: A History of Americanist Anthropology (Lincoln: University of Nebraska Press).

Forster, E.M. [1910] (2013), Howards End (New Jersey: J. P. Piper Books).

Grimshaw, A. (1989-1990), 'A Runaway World?: Anthropology as a Public Debate', The Cambridge Journal of Anthropology, special issue: 'Edmund Leach', 13, no. 3: 75-9.

Haraway, D. J. (2008), When Species Meet (Minneapolis: University of Minnesota Press).

Harper, D. (2002), 'Talking about Pictures: A Case for Photo Elicitation', Visual Studies 17, no. 1: 13-26. doi: 10.1080/14725860220137345

Kelty, C. (2009), 'Collaboration, Coordination, and Composition: Fieldwork after the Internet', in Fieldwork Is Not What It Used to Be: Learning Anthropology's Method in a Time of Transition, (ed.) J. Faubion and G. Marcus (Ithaca: Cornell University Press), 184-206.

Knight, J. (ed.) (2005), 'Introduction', in Animals in Person: Cultural Perspectives on Human-animal Intimacies (Oxford: Berg).

Leach, E. (1967), 'Only Connect ...', A Runaway World, BBC, http://www.bbc.co.uk/programmes/p00hbbpl (accessed 15 September 2015).

Marcus, G. (1995), 'Ethnography in/of the World System: The Emergence of Multi-sited Ethnography', Annual Review of Anthropology no. 24: 95-117. 
Marcus, G. and M. Fischer (eds.) (1986), Anthropology as Cultural Critique: An Experimental Moment in the Human Sciences (Chicago: University of Chicago Press).

Owen, G. R. (2003), ‘What! Me a Spy?: Intrigue and Reflexivity in Zanzibar', Ethnography 4: 122-44. doi: $10.1177 / 1466138103004001006$

Rapport, N. (2009), "“The Human” as the Issue of Anthropology', Anthropologica 51, no. 1: 109-14.
Tambiah, S. J. (2002), Edmund Leach: An Anthropological Life (Cambridge: Cambridge University Press).

Wolf, E. (1980), 'They Divide and Subdivide and Call It Anthropology', New York Times, 30 November. 